\title{
Cuidado de crianças em acolhimento institucional: relações afetivas e dimensão temporal
}

Cuidado de niños en acogida institucional: relaciones afectivas y dimensión temporal Care of children in institutional shelter: affective relationships and temporal dimension

Isabela Cristina Lemos

Universidade de Santa Cruz do Sul, Rio Grande do Sul/Brasil

Roselaine Berenice Ferreira da Silva

ORCID: https://orcid.org/0000-0002-1596-3104

Universidade de Santa Cruz do Sul, Rio Grande do Sul/Brasil

\begin{abstract}
Declaração de Direito Autoral
A submissão de originais para este periódico implica na transferência, pelos autores, dos direitos de publicação impressa e digital. Os direitos autorais para os artigos publicados são do autor, com direitos do periódico sobre a primeira publicação. Os autores somente poderão utilizar os mesmos resultados em outras publicações indicando claramente este periódico como o meio da publicação original. Em virtude de sermos um periódico de acesso aberto, permite-se o uso gratuito dos artigos em aplicações educacionais e científicas desde que citada a fonte conforme a licença CC-BY da Creative Commons.
\end{abstract}

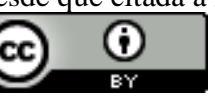

Creative Commons Atribuição 4.0 Internacional.

\section{Resumo}

O presente artigo parte de uma pesquisa qualitativa que objetivou conhecer a relação da profissional cuidadora com os bebês e as crianças pequenas que se encontram em uma instituição de acolhimento localizada no interior do Rio Grande do Sul. Procurou-se enfocar as percepções das profissionais sobre o seu trabalho com bebês e crianças pequenas, em relação aos aspectos afetivos e do cuidado. Os instrumentos utilizados foram as entrevistas semiestruturadas com as cuidadoras que trabalham com a faixa etária do zero aos três anos e observações do cotidiano institucional. Os dados coletados foram analisados pela análise de conteúdo sendo construídas duas categorias de análise. A primeira aponta para um aspecto da relação evidenciado pelas cuidadoras, as rupturas frequentes e a percepção de fracasso, no que diz respeito a sua relação com os bebês e crianças pequenas. Aponta-se um possível sofrimento emocional nessas profissionais e enquanto possibilidade de defender-se apresentam atitudes mais distantes afetivamente. Esse outro ponto é discutido na segunda categoria, que expõem questões da dimensão temporal e das impossibilidades percebidas pelas profissionais frente ao estabelecimento de relações mais próximas com os bebês e crianças pequenas. Entretanto, outras falas sugerem possibilidades no cotidiano do abrigo nos momentos em que as cuidadoras conseguem reconhecer singularidades de cada bebê e criança pequena dentro deste contexto coletivo de cuidado. Aponta-se a importância de seguir pensando e refletindo nesses encontros que acontecem nas instituições de acolhimento, para que estes sejam marcados por relações afetivas significativas e de qualidade.

Palavras-chaves: Cuidador; Crianças; Acolhimento Institucional; Relações Afetivas.

\section{Resumen}

El presente artículo parte una investigación cualitativa que objetivó conocer la relación de la profesional cuidadora con los bebés y los niños pequeños que se encuentran en una institución de acogida localizada en el interior del Río Grande del Sur. Se procuró enfocar las percepciones de los profesionales sobre su trabajo con los bebés y los niños pequeños en relación a los aspectos afectivos 
y del cuidado. Los instrumentos utilizados fueron las entrevistas semiestructuradas con los cuidadores que trabajan con a franja etária de cero a tres años y observaciones de lo cotidiano institucional. Los datos recolectados fueron analizados por el análisis de contenido siendo construidas dos categorías de análisis. La primera de ellas apunta a un aspecto evidenciado por las cuidadoras, las rupturas frecuentes y la percepción de fracaso, en lo que se refiere a su relación con los bebés y los niños pequeños. Se apunta un posible sufrimiento emocional en esas profesionales y en cuanto posibilidad de defenderse presentan actitudes más distantes afectivamente. Este otro punto es discutido en la segunda categoría, que exponen cuestiones del dimensión temporal y de las imposibilidades percibidas por las profesionales frente al establecimiento de relaciones más cercanas. Sin embargo, otras palabras sugieren posibilidades en el cotidiano del refugio en los momentos en que las cuidadoras logran reconocer singularidades de cada bebé y niño pequeño dentro de este contexto colectivo de cuidado. Se apunta la importancia de seguir pensando y reflexionando en esos encuentros que ocurren en las instituciones de acogida, para que éstos estén marcados por relaciones afectivas significativas y de calidad.

Palabras claves: Cuidador; Los Niños; Acogida Institucional; Relaciones Afectivas.

\begin{abstract}
This article sets out a qualitative research that aimed to know the relationship of the caregiver professional with infants and young children who are in a shelter institution located in the interior of Rio Grande do Sul. It was sought to focus the perceptions of the professionals on their work with infants and young children, regarding affective aspects and care. The instruments used were semistructured interviews with caregivers who work with the age range from zero to three years and observations of institutional daily life. The data collected were analyzed by content analysis and two categories of analysis were constructed. The first one points to an aspect evidenced by the caregivers, the frequent ruptures and the perception of failure, with respect to their relationship with infants and young children. A possible emotional suffering is pointed out in these professionals and while the possibility of defending oneself has more distant affective attitudes. This second point is discussed in the second category, which exposes issues of temporal dimension and the perceived impossibilities of professionals in establishing closer relationships with infants and young children. However, other lines suggest possibilities in the shelter's daily life at times when caregivers can recognize the singularities of each infant and young child within this collective context of care. It is pointed out the importance of continuing to think and reflect in these meetings that take place in the shelter institutions, so that these are marked by significant and quality affective relationships.
\end{abstract}

Keywords: Caregiver; Children; Institutional Sheltering; Affective Relationships.

\section{Introdução}

O presente artigo foi construído a partir de uma pesquisa qualitativa que objetivou compreender a relação da profissional cuidadora, no que diz respeito aos aspectos afetivos e do cuidado, com os bebês e as crianças pequenas que vivenciam o contex to de acolhimento institucional. Atualmente é o Estatuto da Criança e do Adolescente - ECA (Brasil, 1990) que organiza, coordena e baliza as ações e cuidado referente a crianças e adolescentes. Dessa forma, o acolhimento institucional compõe o estatuto enquanto uma medida de proteção àqueles (bebês, crianças e adolescentes) que tiveram ameaçado ou violado seus direitos ou quando a família de origem não apresenta condições para cuidar.

Em relação ao histórico das práticas de acolhimento, no Brasil, o século XX é marcado por uma cultura de institucionalização, que levava a criança pobre aos internatos, categorizados enquanto órfãos, abandonados ou delinquentes. Assim, o afastamento do meio familiar e do convívio com a comunidade eram 
práticas frequentes especialmente relacionadas as famílias pobres, sendo o Código de Menores de 1927 considerado um marco nesta época. (Rizzini e Rizzini, 2004). Por meio de parâmetros da Organização das Nações Unidas (ONU) a partir da metade do século XX essa cultura passou a ser questionada, o que culminou após diversas discussões, com o ECA promulgado em 13 de julho de 1990 com a Lei 8.069.

As mudanças advindas do ECA (Brasil, 1990) são relevantes no sentido de procurar superar uma postura assistencialista, pois, hoje se considera que as crianças separadas das famílias precisam mais do que apenas os cuidados básicos como alimentação, higiene e saúde. Tão relevante quanto, são os cuidados afetivos, a convivência familiar e comunitária e o respeito a singularidade. (Nogueira, 2011). A partir desse contexto, passa-se a ser evidenciado o princípio a proteção integral à criança e ao adolescente. Cabe apontar, entretanto, que as motivações para as situações de acolhimento permanecem muito semelhantes as anteriores: a pobreza e o abandono. No entanto, muitas pessoas continuam crendo exclusivamente na incapacidade, tomando as famílias que tiveram seus filhos acolhidos sob uma perspectiva estigmatizante. Mas, se as motivações para o acolhimento ainda se mostram parecidas, há um questionamento sobre as intervenções existentes no contexto social. (Cintra, 2010).

Atualmente, o espaço de acolhimento deve ter um clima residencial, caraterizado por uma moradia digna, com atendimento personalizado, bem como deve ser uma medida de caráter provisório. Quando há necessidade de acolhimento, busca-se a manutenção dos vínculos com a família, procurando primeiramente o retorno a família de origem ou extensa. Somente após a destituição do poder familiar é que existe o encaminhamento para adoção. (Brasil, 1990). Especificamente, em relação ao acolhimento da faixa etária do zero aos três, percebeu-se a partir da pesquisa de Moura e Amorim (2013) que no Brasil, a produção de estudos que envolve bebês e crianças pequenas sob contex to de acolhimento institucional é baixa. Todavia, frente as diferentes faixas etárias da infância, os anos iniciais do ser humano são considerados por especialistas enquanto período de extrema relevância para o desenvolvimento psíquico e dessa forma, diversos estudos têm sido realizados desde a metade do século XX, enfatizando os riscos da institucionalização nesta faixa etária para a saúde mental. (Cavalcante, 2008).

Bowlby (1952/2006), por exemplo, discutiu os efeitos que a privação e o cuidado materno têm na criança, relacionando essa privação a efeitos negativos a saúde mental, considerando que a qualidade dos cuidados no começo da vida pode determinar a capacidade de se apegar ou se vincular a alguém. Além dele, Spitz (1979), a partir dos seus estudos apontou que a privação do cuidado materno no primeiro ano de vida e a vivência em instituição é prejudicial para o bebê e a criança pequena, tendo um caráter traumático. Após anos de pesquisa em ambientes institucionais este autor expõe que o primeiro ano de vida se refere ao período de maior plasticidade no desenvolvimento do ser humano. Assim, apesar de sofrerem críticas ao longo dos anos, estes são autores pioneiros que colocaram em voga a importância do afeto e de relações de qualidade no começo da vida.

Destarte, Cavalcante (2008) expõe o tom paradoxal que permeia as discussões em relação ao cuidado nos ambientes institucionais. Se por um lado os abrigos compõem a rede de proteção à criança e ao adolescente, frente as diferentes impossibilidades de cuidado pela família de origem. Por outro, se apontam os possíveis riscos que o cuidado prolongado em instituições pode trazer ao desenvolvimento global. A autora, em sua pesquisa, considera o abrigo enquanto contexto de desenvolvimento e de cuidado a partir de uma perspectiva ecológica, analisando que além de sofrer influências dos cuidadores e dos pares, a criança é ativa, protagonista, provoca alterações e mudanças nas dinâmicas interacionais, e, portanto, no seu próprio desenvolvimento. Ainda, Siqueira e Dell'Aglio 
(2010) que também consideram o abrigo através de uma perspectiva ecológica, apontaram a partir de seu estudo, que o tempo de institucionalização pode trazer prejuízos especialmente em relação a proximidade com a rede de apoio. Nesse sentido, enfatizam a necessidade de construir mecanismos sociais que garantam a provisoriedade do período de acolhimento, visando que os efeitos de tempo prolongados nos abrigos sejam menores.

Conforme Alencar (2015) os bebês e crianças pequenas afastados da figura materna trazem enquanto demanda a fundamental a presença de um adulto cuidador capaz de formar vínculos e realizar cuidados afetivos. Os bebês e crianças pequenas que estão sob acolhimento institucional vivenciam uma fase da vida de constituição. O cuidador desta faixa etária tem diante de si a tarefa de cuidar e educar, e, além disso, perceber no dia a dia as dificuldades e as conquistas. Compreende-se que o processo de se tornar pessoa, "acontece a partir da relação do bebê com aqueles que dele cuidam e através de um complexo processo de desenvolvimento. Não basta esperar a passagem do tempo para que tudo isso aconteça de forma automática". (Alencar, 2015, p.16).

Ao entendermos esse ponto crucial é possível refletir com Gabeira e Zornig (2013) que apontam que o cuidado com bebês e crianças pequenas é diferente em muitos aspectos do cuidado de crianças mais velhas e adolescentes. $\mathrm{O}$ desenvolvimento psíquico do bebê e da criança pequena depende especialmente de um adulto cuidador disponível. Dentro de uma realidade de acolhimento institucional são os cuidadores que assumem a responsabilidade pelas tarefas de cuidado. Portanto, com o passar dos dias são eles que estão no cotidiano percebendo e acompanhando o crescimento destas crianças e participando da sua constituição como sujeitos, visto que o tempo que deveria ser provisório muitas vezes acaba não sendo, conforme Cintra (2010) nos aponta. Entretanto, constata-se que ainda há falta de formação, capacitação continuada e espaço de escuta para estes profissionais. (Cavalcante, 2008; Careta, 2011).
Dessa forma, esse artigo é resultado de uma pesquisa com cuidadoras que trabalham diretamente com a faixa etária do zero aos três anos em ambiente de acolhimento institucional em que se procurou, enquanto objetivo geral, conhecer aspectos da relação desse par. Assim, o cuidado $\mathrm{e}$ as relações afetivas foram enfocados a partir da percepção das cuidadoras frente a relação que estabelecem com os bebês e crianças pequenas. Realizar uma pesquisa abrangendo bebês e crianças pequenas que vivenciam um contexto de acolhimento demonstra um envolvimento com as questões de saúde mental e os primeiros anos de vida trazidas em diferentes disciplinas no decorrer da formação em psicologia. Entretanto, conforme Winnicott (1982) afirma, um bebê ou uma criança ainda pequena não existe sozinha, e é assim que a figura dos cuidadores ganha destaque nessa dinâmica.

Os cuidadores são personagens que ocupam um espaço extremamente importante nas instituições de acolhimentos e mais especificamente na vida dos sujeitos que tiveram parte das suas vidas interpeladas pela vivência em ambiente institucional, o que implica para as crianças, em anterior abandono, violência e quaisquer formas de violação ou ameaça de direitos. (Nogueira, 2011). No entanto, apesar da instituição de acolhimento ser considerada uma medida de proteção há em todo esse contexto, uma outra forma de violência e violação de direito, que é a impossibilidade de que as crianças convivam com uma família, construindo relações mais íntimas e calorosas. Nesse sentido, os autores Rossetti-Ferreira et al. (2012) percebem um grande impasse na questão dos vínculos das crianças quando estas estão acolhidas, pois por um lado pouco consegue se efetivar na manutenção e (re)construção de vínculos com sua família de origem ou extensa. Entretanto, por outro lado, o número normalmente insuficiente de cuidadores, somado a um pessoal pouco qualificado pode prejudicar a qualidade das relações existentes nesse contexto.

A partir do ECA (Brasil, 1990), do Plano Nacional de Convivência Familiar e 
Comunitária (PNCFC) de(Brasil, 2006), do Documento de Orientações Técnicas para Crianças e Adolescentes, (Conselho Nacional dos Direitos da Criança e do Adolescente [CONANDA]/Conselho Nacional de Assistência Social [CNAS], 2009), se tem avançado em diversas discussões sobre o acolhimento institucional. Especialmente em relação a importância de um cuidado integral, da convivência familiar e comunitária, bem como em mudanças de práticas e ações dentro das instituições de acolhimento, visando menores prejuízos em relação ao período de acolhimento. Tais mudanças partem de uma percepção diferente de criança enquanto um ser de direitos, assim,

Se as mudanças que vem sendo propostas apontam para um futuro mais promissor para o cuidado substituto de crianças e adolescentes no Brasil, há que se lembrar que a construção das medidas de proteção integral e das políticas de assistência ainda estão em processo. Esforços permanentes serão necessários até que se consiga de fato produzir rupturas e criar novos caminhos que potencializem a integralidade e a intersetorialidade da atenção à criança e ao adolescente e promovam seu direito à vida familiar e comunitária. (Luvizaro \& Galheigo, 2011, p. 194).

Segundo o Documento de Orientações Técnicas: Serviços de Acolhimento para Crianças e Adolescentes, (CONANDA/CNAS, 2009) o uso da palavra cuidador ou educador serve para designar a mesma função, aquela pessoa que está no contato diário com a criança ou adolescente na instituição de acolhimento com foco no cuidar e educar. Em relação a faixa etária do zero aos três anos o ECA (Brasil, 1990) traz em seu Art. 92. § 7o, algumas especificidades para atuação dos educadores, que deve procurar manter educadores de referência que sejam qualitativamente significativos, além da atenção as rotinas de cuidado básica, com enfoque prioritário as necessidades afetivas.
Gabeira e Zornig (2013) apontam que a profissão de cuidador é desafiadora, pois em muitos casos nas instituições não há preparo, formação e espaços de escuta. Assim, como forma de nortear esse trabalho as autoras afirmam que a ênfase deste deve ser dada na observação das conquistas do bebê e de seu desenvolvimento ao invés da ênfase na emoção. Tal posicionamento pode vir a favorecer o trabalho e a relação com o bebê. Ainda Zornig (2010) aponta que o contato com o bebê e a criança pequena pode mobilizar questões arcaicas que tende a gerar um distanciamento afetivo prejudicial as crianças. Contudo, Alencar (2011) menciona que é preciso que o cuidador perceba o bebê e as crianças pequenas com suas particularidades, diferenças e preferencias, o que dará a possibilidade de que exista uma rede de significados com sentidos próprios e singulares na relação com cada bebê.

Segundo Cavalcante, Magalhães e Pontes (2007) a relevância da existência de pesquisa em contexto de acolhimento institucional de bebês se dá pelo fato de que a partir destas que nos é possibilitado pensar sobre formas de exercer um cuidado infantil e que este cuidado possa ser "rico em possibilidades humanas" (Cavalcante et al., 2007, p. 336). Retoma-se a importância de conhecer as relações estabelecidas pelas cuidadoras com os bebês e crianças pequenas a partir da perspectiva dessas profissionais, pois Careta (2011) amparada pela teoria winnicotiana, expõe que as cuidadoras representam o ambiente humano circundante das crianças acolhidas. No momento do acolhimento, este representa o ambiente possível para alguns sujeitos, que se saudável pode vir a favorecer o desenvolvimento das potencialidades.

\section{Método \\ Delineamento da pesquisa}

A pesquisa foi realizada a partir de uma perspectiva qualitativa, segundo Gibbs (2009) esse tipo de pesquisa de modo geral pretende ter acesso às interações e experiências, procurando conhecer o modo como as pessoas constroem o mundo e vivem nele, bem como o 
modo como as relações se estabelecem em determinados contextos. Assim, sendo que o foco da pesquisa foi conhecer aspectos da relação do cuidador com os bebês e crianças pequenas, assim como as percepções sobre as relações afetivas e sobre o cuidado, compreende-se que a pesquisa qualitativa correspondeu aos objetivos da pesquisa.

\section{Participantes}

A pesquisa ocorreu em uma instituição de acolhimento localizada no interior do Rio Grande do Sul (RS), esta instituição acolhe crianças de zero a 12 anos. A pesquisa se deu na casa-lar que acolhe bebês e crianças pequenas de zero a três anos. Dessa forma, os cuidadores desta faixa etária constituíram-se enquanto sujeitos da pesquisa. Contudo, pensando que o enfoque da pesquisa é a relação desse par cuidador-bebê ou cuidador-criança pequena, as crianças da faixa etária do zero aos três anos que estavam em situação de acolhimento institucional no momento da coleta de dados também estiveram dentro da pesquisa. Tal participação se dá pelo fato de que além das entrevistas com os cuidadores se utilizou da observação do contexto de acolhimento institucional.

A amostragem dentro da pesquisa qualitativa normalmente é orientada com o intuito de encontrar pessoas que se encaixem no foco da pesquisa, sendo assim, é uma amostragem intencional. Primeiro se contatou a coordenadora da instituição de acolhimento, para que se pudesse chegar até os cuidadores da instituição. Foram realizadas um total de cinco entrevistas, tendo como requisito o contato, no trabalho diário, com crianças do zero aos três anos idade, já que conforme explicitado, a instituição acolhe outras faixas etárias também. As cuidadoras entrevistadas eram mulheres, das cinco todas elas eram mães e já tinham experiências cuidando de crianças, seja em ambiente familiar ou coletivo, o que é prérequisito para contratação na instituição, entretanto, nenhum tipo de formação específica é exigido. As entrevistadas serão identificadas pela numeração de um a cinco para discussão dos resultados.

\section{Instrumentos}

Para realização da pesquisa se utilizou enquanto instrumento as entrevistas semiestruturadas com os cuidadores dos bebês e crianças pequenas que estão cotidianamente em contato com estes. Segundo Gaskell (2003) essa técnica é um meio potente para compreensão das relações em determinados contextos, visto que seu objetivo é conhecer detalhadamente os valores, atitudes, crenças e motivações dos sujeitos da pesquisa. Entendese ainda que é a partir desse instrumento que é o pesquisador tem a possibilidades conhecer o modo como as pessoas constroem sua vida cotidiana e o seu mundo vivencial. Corroborando para que compreendamos as percepções das cuidadoras, e dessa forma, aspectos dessa relação com aqueles os quais elas exercem o cuidado.

Nas entrevistas, o meio de troca são as palavras, portanto é uma interação onde entrevistado e entrevistador estão envolvidos e comprometidos com a construção do conhecimento. As entrevistas, mesmo com questões já delimitadas, "são quase que um convite ao entrevistado para falar longamente, com suas próprias palavras e com tempo para refletir" (Gaskell, 2003, p. 73).

Também foi utilizado enquanto procedimento a observação de momentos cotidianos de cuidado, onde foram observados três turnos de trabalho. Segundo Bentzen (2012) o procedimento da observação é fundamental basicamente porque quando observamos estamos aprendendo sobre a realidade apresentada. Ao pensarmos na observação que envolve crianças, nesse caso, de bebê e crianças pequenas é preciso ter claro quais são os objetivos dessa observação e no caso dessa pesquisa, se deu em função da compreensão dos aspectos da relação de adultos cuidadores com bebês e crianças pequenas. 


\section{Procedimentos}

As entrevistas semiestruturadas tiveram um roteiro, contudo não foram inflexíveis. $\mathrm{O}$ objetivo desta foi questionar aspectos vivenciais do cuidador na sua relação com bebês e crianças pequenas, além disso, questionamentos acerca do cotidiano no abrigo. Solicitou-se que as cuidadoras falassem a partir de uma pergunta aberta sobre a sua relação com os bebês e crianças pequenas. Também que contassem sobre a sua trajetória na instituição, as motivações para trabalhar neste local, sobre a sua função e sobre seu cotidiano de trabalho com as crianças de zero aos três anos. Foram questionadas as dificuldades e impasses no trabalho, a percepção das contribuições do cuidador nesse contexto e dos fatores que consideram importante para o desenvolvimento dos bebês e crianças pequenas. As entrevistas ocorreram na instituição com cinco cuidadoras que trabalham cuidando de crianças desta faixa etária, sendo todas as entrevistas gravadas e posteriormente transcritas.

A observação, que se deu em três turnos, ocorreu em ambiente de acolhimento institucional, onde após os turnos era realizado um registro escrito. A observação se deu na casa-lar em que estão acolhidas as crianças de zero a três anos; no momento da pesquisa havia cerca de 15 bebês e crianças pequenas dentro dessa faixa etária em situação de acolhimento. Os cuidadores, assim denominados pela instituição trabalham em duplas que se revezam em três turnos de trabalho, manhã, tarde e noite. Em cada turno há tarefas especificas a serem cumpridas que envolvem também a organização da casa. Nesse sentido, foi observado um turno da manhã, um da tarde e um da noite. Compreendeu-se as implicações que a presença da pesquisadora teria no campo, ou seja, não seria uma presença neutra, assim, objetivou-se nesses turnos de observação acompanhar o cotidiano da casa-lar. Os momentos de troca de fraldas, de banho, de alimentação são exemplos de momentos observados, especialmente, observando se o cuidador estava em relação, ou seja, conversando, comentando e estabelecendo significações as ações dos bebês e das crianças pequenas.

\section{Análise dos dados}

Para analisar os dados coletados se utilizou a Análise de Conteúdo de Bardin (1977) que consiste em uma técnica de análise de diferentes fontes de conteúdo que tem o intuito em compreender por meio de categorias de análise o que está sendo dito por trás dos discursos. Nesse sentido, é importante ressaltar que o material analisado partiu das entrevistas individuais que foram transcritas em sua totalidade e de registros da observação. Tal perspectiva de análise indica que os textos obtidos pela coleta de dados, nesse caso a partir das transcrições completas das entrevistas devam ser categorizados objetivando que se possa conferir significação ao material. Essa técnica refere-se tanto ao estudo nos conteúdos manifestos, mas também latentes e das figuras de linguagem, nesse sentido, a semântica é um entendimento necessário, visto que se refere a pesquisa do sentido de um texto.

Essa metodologia de análise dos dados é composta por algumas etapas que foram seguidas nessa pesquisa através de Bardin (1977). Primeiramente se parte da pré-análise, a qual é composta pela leitura flutuante dos materiais e preparação inicial destes, onde se realiza a formulação de hipóteses iniciais e possíveis indicadores de análise. Nesse momento foi empreendida a leitura de todo o material coletado de forma "despretensiosa", onde procurou-se conhecer o significado geral do conteúdo das transcrições e se deixam livres as impressões. Essa leitura é o caminho para o segundo passo, contribui para encontrar mesmo que de forma inicial indícios e pistas que não estão dadas.

Depois dessa etapa, parte-se para a fase de exploração do material em que se fez necessário realizar um agrupamento e codificação dos dados. Nesse sentido, o material coletado foi recortado em unidades de registro, ou seja, palavras, frases e parágrafos, 
reunindo-os tematicamente para que se pudesse formular as categorias de análise. Ao final, a terceira etapa consistiu em analisar as categorias finais a partir do escopo teórico existente, onde o intuito é a produção de outras reflexões, dessa forma, foi o momento em que tais categorias foram analisadas.

\section{Considerações éticas}

Primeiramente foi estabelecido contato com a coordenadora da instituição de acolhimento para explicar os objetivos da pesquisa e receber uma autorização. Assim, após encaminhar o projeto de pesquisa ao Comitê de Ética em Pesquisa (CEP) através do cadastro na Plataforma Brasil e receber um parecer favorável, iniciou-se a mesma. Todas as participantes assinaram o Termo de Consentimento Livre e Esclarecido, ou seja, compreendendo de forma clara os objetivos da pesquisa, os possíveis desconfortos, tendo sido esclarecido dúvidas quanto a pesquisa.

\section{Resultados e discussão}

As duas categorias de análise discutidas nesse artigo referem-se as percepções das profissionais cuidadoras sobre a relação que estabelecem com os bebês e crianças pequenas que se encontram acolhidos. A primeira diz respeito a realidade institucional, marcada constantemente por rupturas de vínculos $\mathrm{e}$ necessidade de construir novas relações com a chegada de uma criança. Essa categoria serve de base para pensarmos a seguinte, onde discute-se sobre as percepções das profissionais frente ao que se estabelece na rotina dos bebês e crianças pequenas e aos aspectos da sua relação afetiva com estes.

\section{A relação afetiva: as rupturas e o sentimento de fracasso}

Essa categoria reflete sobre as percepções das cuidadoras frente 0 desenvolvimento do seu trabalho, especificamente sobre a sua relação com os pequenos sujeitos que é permeado por separações, mas que, por outro lado, necessita de disponibilidade para construção de novos vínculos, devido ao acolhimento de novas crianças. Ao explorar com as cuidadoras acerca das relações que estabelecem no abrigo, sobre as suas trajetórias e as dificuldades encontradas nesta profissão, se evidenciou pelo agrupamento em unidades de análise e posterior construção da categoria, conteúdos que implicam no envolvimento emocional das profissionais. Tais aspectos dizem respeito as separações que permeiam a realidade institucional, bem como sentimentos de fracasso decorrentes da percepção de não estarem conseguindo realizar um trabalho que pensam ser o adequado.

As histórias contadas em relação as separações envolvem muito afeto e emoção, mesmo que muitas dessas situações ocorreram há anos atrás. Desse modo, a partir dos relatos das cuidadoras, dentre os aspectos afetivos que compõem as relações que são construídas no espaço de acolhimento, as frequentes separações e rupturas mostraram-se relevantes para refletirmos. Algumas falas serão expostas abaixo:

Cuidadora 3: E hoje em dia, quando eu falo, olha eu já tenho que chorar (...) eu vi ele vindo pra cá com oito meses... Aí eu me emociono demais com ele. Ele veio pra cá com oito meses bem debilitado ficou três meses no hospital, quase morreu (...) daí levaram ele pra Porto Alegre, ah foi muito triste, porque eu criei ele aqui comigo, né.

Cuidadora 5: (...) Então a gente viu ela crescer, a gente viu ela engatinhar, a gente viu sabe... Todo o desenvolvimento... Quando ela for assim, vai ser bem difícil, tanto pra ela quanto pra gente, né, porque o que ela conhece é as tias, o que ela conhece é a gente, então vai ser bem complicado né, pra gente também. Porque a gente criou, desde muito pequenininha.

Em relação as rupturas de vínculos, pode-se pensar, a partir de Tinoco (2007) que estas remetem a processos de luto. É expresso 
pelas profissionais que o convívio com uma criança desde os primeiros meses da sua vida, implica na construção de uma relação, onde a cuidadora passa a acompanhar uma vida, a reconhecer seus gostos e suas particularidades. Com esse panorama, entende-se que há um investimento grande por parte das cuidadoras e assim, a partida dos bebês e crianças pequenas tem o potencial de mobiliza-las, considerando que existirão novas situações semelhantes. A adaptação frente a uma perda se configura em um longo processo, que impedido de ser feito de modo saudável, pode contribuir para que as profissionais procurem se defender. É perceptível que existe grande influência dessas separações antigas, e por essas falas também se evidencia que na realidade de acolhimento institucional é possível a formação de vínculos e de relações.

Entretanto, o peso das separações também é demonstrado não só pelo sofrimento por uma quebra de vínculo que já ocorreu. Mas também pelo relato da cuidadora 5 que já sofre por antecedência, se assim pode dizer, em relação a uma menina que a instituição acolhe desde muito bebê e que agora está encaminhada para adoção. As significações na experiência subjetiva dos sujeitos frente aos diferentes momentos da vinculação são comparadas por Bowlby (1990, p. 56) com as seguintes situações: "a formação de um vínculo é descrita como "apaixonar-se", a manutenção de um vínculo como "amar alguém", e a perda como "sofrer por alguém". Devido a isso, segundo o autor, a ameaça de perder um vínculo mobiliza imensamente o sujeito, gerando ansiedade frente a novas situações de perda ou separação de vínculo. Pensando nas frequentes separações trazidas pelos relatos das cuidadoras se observou que as falas também traziam sobre uma necessidade de uma mudança frente a sua postura no período inicial de trabalho na instituição:

Cuidadora 2: Quando eu iniciei foi bem difícil, eu saí muitas vezes daqui chorando, ãh.... até te acostumar... é bem diferente eu tava acostumada com escola, com EMEI's bem diferente, totalmente diferente mesmo.
Cuidadora 1: (...) No começo eu era assim, eu me abalava demais e assim, no decorrer do tempo que eu tô aqui tu vai.. sabe.. procurando te defender um pouco mais contra o teu sentimento com outras coisas sabe, porque tu sabe que é isso que tem ser.

Torna-se necessário refletir sobre o quanto esse envolvimento afetivo mobiliza as cuidadoras e sobre a necessidade de criar mecanismos para se defender dessa realidade. Questiona-se sobre como estão fazendo isso, ou seja, como estão lidando com essa realidade de separações. Aponta-nos Tinoco (2007) a capacidade de lidar com esse contexto certamente depende da história de cada uma das cuidadoras. Caso o cuidador não tenha espaço para falar disso, pode se paralisar dentro dessa relação, visto que também haverá uma nova ruptura futuramente com esse bebê ou criança. O "paralisar-se" pode se transformar em distanciamento, portanto, espaços para falar sobre isso configuram-se para os cuidadores como estratégias fundamentais. (Zornig, 2010). Assim, a atitude de "não se apegar" é apontada pelas cuidadoras entrevistadas enquanto forma de defesa frente as rupturas e diante das complexas experiências no início do seu trabalho.

Cuidadora 4: Se ninguém vai querer trabalhar, ninguém vai querer cuidar deles, como eles vão ficar? Tem que ter alguém e realmente eu não me apego porque é muito ruim depois pra gente.

Na dissertação de Moura (2012) vemos uma semelhança, pois percebeu-se que as cuidadoras também tinham essa postura. Dessa forma, tinham a percepção de que se não se apegassem as crianças, que era expresso no ato de contatos físicos especialmente o pegar no colo, elas não sofreriam com as partidas e despedidas dos bebês e crianças pequenas tão recorrentes nesse contexto. Essas experiências difíceis de separação podem se enquadrar em processo de luto não reconhecidos, conforme nos aponta Tinoco (2007). O profissional 
cuidador vincula-se com a criança e perde o vínculo após sua partida, seja para retorno com a família a de origem ou em família adotiva. Este luto torna-se não reconhecido, pois, aparentemente a cuidadora já deve ter a clareza de que seu papel é temporário e que mesmo que assuma tarefas que lembrem o cuidado parental, elas não são as mães destas crianças. Porém, a tarefa de cuidar bebês e criança pequenas mobiliza questões arcaicas e inconscientes das cuidadoras, conforme aponta Marin (2011) e, portanto, esses processos podem não se tornar tão claros, especialmente em relação ao reconhecimento da sua função, que é temporária.

Assim, França (2008) também coloca que frente a esse contexto de frequentes separações que é o abrigo, há a necessidade de que a profissional cuidadora reconheça que a instituição de acolhimento é para ser um espaço de vivência para o bebê e a criança pequena, enquanto um lugar temporário. Isso implica reconhecer também que mais cedo ou mais tarde as crianças que lá estão voltarão para suas famílias de origem ou serão adotadas. É complexo esse cotidiano visto que, a cada chegada de um bebê a cuidadora compreende que seu papel é cuidar da melhor forma possível, implicando em envolvimento afetivo. Por outro lado, a chegada também reativa o drama de saber que num futuro próximo haverá uma separação e que como ocorreu com as outras.

Esse também foi um dos pontos analisados a partir das entrevistas, visto que as falas sugeriam uma necessidade de estabelecer mais limites frente as percepções sobre o seu papel no abrigo. $\mathrm{O}$ espaço para fala parece ter sido utilizado pelas profissionais enquanto uma possibilidade de expressar sobre as linhas tão tênues que permeiam sua profissão. Pois no seu fazer diário, realizam tarefas de cuidado que remetem ao cuidado parental, e, entretanto, não são mães. Procuram cuidar da melhor forma possível, mas tem medo das separações. Tentam cuidar "como se fossem seus filhos", contudo, uma parte de si mesmas diz que isso não é possível.
Cuidadora 3: Eu faço papel, eu não sei, acho que é papel de mãe, porque eu educo, eu do colo, eu alimento, eu do limite, né, a gente tem que dar tudo que nem uma mãe, eu pra mim eu vejo assim. Só que claro a gente não pode misturar porque a gente é cuidadora né, a gente não é mãe, não dá pra misturar também né. Tu não é mãe, mas tu faz faz o papel de mãe, eu faço tudo o que uma mãe faria, né.

Cuidadora 1: tu tem que te doar sabe, eu acho que tu tem que dar, tirar do que tu tem. É que tipo assim, o que tu tem para dar pros teus filhos tu chega aqui e tu dá também. Procura dar. Pelo menos procura. (...) Teus filho tu consegue fazer tudo aquilo ali entendeu. Tu consegue dar o amor, tu já vem com a tua bagagem... Aqui não.

Cuidadora 4: Dizem que a gente não é pra falar isso, mas eu acho que a gente muitas vezes exerce o papel de mãe aqui dentro.

O trabalho temporário e a dificuldade de compreensão dos papeis contribui para que as cuidadoras se sintam impossibilitadas de responder as demandas dos bebês e crianças pequenas. Cinta (2010) afirma que o lugar de cuidador não é ocupado sem conflitos, especialmente pelo fato de se ocuparem de uma função parental, "pois são e não são as mães; o conflito mescla o discurso técnico racionalizado e o desejo de encarnar esse lugar materno". (Cintra, 2010, p. 89). É por esta razão, que Seguim e Daffre (2006) evidenciam a importância da escuta de profissionais que cuidam de crianças. A falta de espaço para expressar sentimentos pode mobilizar situações frequentes de estresse emocional, o que pode afetar as relações que o cuidador estabelece no contexto de trabalho. $\mathrm{Na}$ instituição em que a pesquisa foi realizada, segundo informações da coordenadora da instituição, as cuidadoras contam com um grupo para todos profissionais, onde participam também profissionais da equipe técnica, porém, foi questionado as entrevistadas da sua participação neste grupo e 
apenas ocorre de maneira esporádica pela cuidadora 1 e cuidadora 5 , sendo que as demais afirmam que seus horários não coincidem com o horário do grupo.

Em relação a clareza do papel atribuído a figura do cuidador foi perceptível que as referências que partem das suas identidades enquanto mães são utilizadas com frequência. Isso pode nos indicar uma dificuldade nesta compreensão que resulta em frustração, pois comparam o cuidado com seus filhos, com aquele que acontece na instituição. Um fator que pode determinar esse sentimento, além da falta de compreensão dos limites da sua tarefa de cuidar é a quantidade de crianças na casa-lar em relação a quantidade de cuidadores, que gera sobrecarga de trabalho. No momento atual da pesquisa existiam cerca de quinze crianças abrigadas de zero a três anos, para um número de duas cuidadoras por turno.

Assim, as cuidadoras têm a percepção de estarem conseguindo realizar as tarefas de cuidado diário em relação as rotinas impostas pela instituição. Porém, o sentimento de fracasso diz respeito a atenção mais relacionada as questões e demandas afetivas dos bebês. Em relação as crianças pequenas, já um pouco maiores há a percepção de não conseguirem realizar brincadeiras e interações com mais tempo. Assim, frente as implicações emocionais, através dessa categoria entende-se que dizem respeito especialmente ao contexto de separações, mas também da percepção de fracasso no cotidiano de trabalho.

Cuidadora 5: É bem complicado porque o foco aqui são as crianças só que tu não consegue dar a atenção que eles precisam sabe, tu realmente não consegue dar atenção, tu não consegue ficar com eles. Tu vê que tu trabalha aqui tipo um robô, tu trabalha aqui aquela rotina e tu não consegue dar um carinho, dar um afeto pra eles, tanto que eles ficam aqui na porta assim, parado ali olhando e te chamando.
Cuidadora 1: Parece que tu nunca fica com o trabalho bem feito sabe, tu não tá lidando com robô entendeu, são criança, são ser humano e eu acho bem complicado. Sinto bastante essas coisas de revolta, bá. E eu gosto de sentar de brincar com eles, eu gosto de fazer isso, aí me deito lá nos colchonetes deles e eles vem tudo pra cima da gente e eu gosto de brincar, eles esperam isso da gente né, principalmente ali no berçário eles exigem isso de ti que eles tão toda hora te chamando. Querem atenção né? E tu não consegue dar. Bá, "que que tu quer né, fala?”, mas não é aquilo de tu sentar, tu não tem esse tempo sabe, mas seria bom se tivesse.

Assim, quando sentimentos intensos de fracasso e de culpa atingem as profissionais é possível que elas rejam, de forma defensiva. Podem existir sentimentos hostis e agressivos conscientes, mas também inconscientes, frente as crianças com as quais não estão conseguindo suprir as demandas, o que leva a necessidade de distanciar-se, assim, "É contra esse tipo de fracasso que a cuidadora, muitas vezes, elabora atitudes de distanciamento que a protegem de todo engajamento afetivo em relação a criança". (França, 2008, p. 94). Ainda, avaliando que a realidade institucional pode mobilizar as profissionais, a partir das rupturas e da frustração com seu trabalho, compreendese a importância de cuidar da saúde mental das cuidadoras, visto que, conforme a tese de Careta (2011) as cuidadoras representam o ambiente humano que pode favorecer ou não o desenvolvimento daqueles que estão no abrigo. Nesse ponto, a saúde emocional das mesmas que reflete nas possibilidades desse contex to ou não.

\section{Dimensão temporal e as implicações para os bebês e crianças pequenas}

A categoria da dimensão temporal e as implicações para os bebês e crianças pequenas expressa as percepções das cuidadoras acerca das impossibilidades nesse cotidiano de 
trabalho coletivo com bebês e crianças pequenas. As cuidadoras apontam que conseguem cumprir com as reponsabilidades com a rotina, com as ações de cuidado em geral com os bebês e crianças pequenas, que envolve também a preparação dos alimentos e a organização da casa. Nesse sentido, as falas sugerem certa frustração das cuidadoras por não conseguirem ampliar o cuidado, ficando centralizado apenas no cuidado com questões básicas de higiene e alimentação, que segundo Albano (2011) são momentos potentes e de importância primordial para a construção de uma rede de sentidos singulares; porém não na percepção das mesmas. A Cuidadora 1 falando acerca da rotina:

Cuidadora 1: (...) Mas fica sempre nisso aí né, essa é a rotina, então a gente é bem no automático a gente já entra e já sabe o que tem que fazer. A gente trabalha entre duas, é eu e minha outra colega, então a gente já entra e já sabe o que cada uma tem que fazer. $O$ que não tem tempo assim é de tu as vezes agarrar uma criança, tu brincar direito, tu não consegue ter isso aí ainda, que é muita criança e os pequenos exigem muito da gente também, os nenês.

Entretanto, esses momentos de cuidado com o corpo são momentos são ricos e cheios de possibilidade se realizados com qualidade, pois são nesses momentos que há um estreitamento do vínculo, são ações atravessadas pelo toque, pelo olhar e pela palavra. (Alencar, 2015). Entretanto, na percepção das cuidadoras é como se estivessem fazendo pouco. A cuidadora 3 aponta sobre as principais contribuições da profissional cuidadora, mas que, entretanto, devido a rotina institucional, tornam-se difíceis de serem realizados:

Cuidadora 3: A gente contribui mais cuidando e principalmente dando colo, dando carinho, dando amor, os maiores dando limites, porque eles já têm que ter, eles tem que ter limite também aqui os grandes tão totalmente fora de limite. Justamente por falta de tempo nossa. Porque a gente tem muito pouco tempo pra eles né.

$\mathrm{Na}$ percepção das cuidadoras as ações são divididas entre o cuidado que se refere as necessidades físicas e outro referente as necessidades afetivas dos bebês e crianças pequenas. As falas apontam que não existe tempo para conversar, para brincar, para dar atenção. Ou seja, apenas o cuidado referente às questões de rotina está sendo realizado. Segundo Luvizaro e Galheigo (2011) a vida cotidiana pode ser perpassada pelas possibilidades de criação, mas por outro lado, pode se cristalizar em repetições pobres, onde a potência criativa pouco existe. Nas entrevistas a menção sobre essas impossibilidades no cotidiano foi frequente, sendo mencionado em duas entrevistas a ideia de "trabalhar como um robô", (cuidadora 1 e 5), pois precisam dar conta das rotinas preestabelecidas. Com isso, podemos entender que os momentos que ocupam grande parte do dia, que dizem respeito as necessidades físicas dos bebês e crianças pequenas, não são investidos pelas profissionais enquanto momentos ricos de trocas, interação, inclusive de investimento afetivo.

Nesse sentido, chegamos nas considerações dos pesquisadores sobre o que é importante no cotidiano de um bebê e criança pequena, não no sentido de avaliar o cuidado prestado pelas profissionais, porém, no intuito de pensarmos nas implicações aos bebês e crianças pequenas. Gabeira e Zornig (2013) colocam acerca do que é preciso no cotidiano do bebê, que a maior parte das experiências diárias do bebê devem ser permeadas por momentos de interação. Além de considerarem que é tarefa dos agentes de cuidado organizarem o ambiente de forma que facilite as experiências sociais das crianças. As falas das cuidadoras implicam a noção da dimensão temporal em relação a necessidade de dar conta das rotinas estabelecidas. Nesse sentido, Brazelton e Greenspan (2002) que falam sobre as necessidades essenciais das crianças, 
expõem que na maior parte do tempo em que o bebê está acordado, o ideal é que ele esteja na presença de adulto cuidador. Caso isso não seja possível, que nos momentos em que ele está desperto é preciso ao menos facilitar a exploração do espaço.

As observações realizadas na instituição mostram que a realidade institucional não permite todos esses momentos de interação, conforme descrito na literatura. Normalmente, após realizarem tarefas como o banho e alimentação, tanto os bebês como quanto as crianças de cerca de um ou dois anos ficam em salas diferentes. Nessas salas existem brinquedos pelo chão, onde se procura que eles estejam adequados as faixas etárias. As cuidadoras procuram atender primeiramente os chamados dos bebês e aquilo que está na rotina, respeitando os horários de banho e alimentação, por exemplo. A divisão do espaço no berçário também não facilita que os cuidadores estejam no campo visual dos bebês e crianças pequenas, pois é um espaço muito dividido por diferentes salas. Entretanto, na perspectiva de Cavalcante (2008) as trocas dos pares são extremamente ricas, o que nesse contexto pesquisado representa uma possibilidade, pois existem diversos momentos de interação entre crianças da mesma idade no decorrer do dia.

É importante ressaltar referente ao desenvolvimento cognitivo que os objetos não são estimulantes em si, a companhia de um educador nesses momentos para criar e brincar é enriquecedora e extremamente necessária. (Albano, 2011). Assim, essas impossibilidades no cotidiano da instituição, de certo modo apontam que a integralidade do cuidado às necessidades da criança dentro dos contextos institucionais como estabelece o ECA (Brasil, 1990), ainda estão em processos de adequação, conforme nos apontam Luvizaro e Galheigo (2011). Além do ECA, há também o Documento de Orientações Técnicas para Serviços de Crianças e Adolescentes (CONANDA/CNAS, 2009) que estabelece a necessidade de cuidado integral.

O cuidado referente apenas as necessidades físicas dos bebês e das crianças pequenas remete a questões históricas das práticas de acolhimento. Foi somente a partir do ECA (Brasil, 1990) o sistema de proteção passa da função de assistir, que remete muito mais a uma postura assistencialista de suprir necessidades físicas, à função do acolher, ou seja, do cuidado integral das necessidades das crianças e adolescentes. (Nogueira, 2011). Contudo, é possível fazermos outra leitura acerca das questões de falta de tempo trazidas por todas as entrevistadas, especialmente pensando sobre a fala de uma cuidadora refletindo acerca da necessidade ou não de mais funcionários:

Cuidadora 3: às vezes eu não tinha
nada o que fazer, entendeu? Aí não
tem como eles pegar funcionário
porque quando vê uma hora eles vão.
Aí não tem como eles pegar
funcionário e quando ver largar é
muito custo né, uma que elas
(instituição) vivem de doação né, tem
que ser tudo controlado.

A realidade institucional referente a quantidade de crianças acolhidas está em constante mudança, visto que o acolhimento representa esse momento de espera entre o voltar para a família de origem ou o encaminhamento para adoção (Cavalcante, 2008). Assim, as cuidadoras reconhecem que existem momentos que a quantidade de crianças é muito menor, entretanto, a postura frente ao modo como cuidam não parece mudar, no sentido de investir mais em momento de afeto, de narratividade. Assim, Gabeira e Zornig (2013) destacam a diferenciação entre o fundamento da relação materna e da relação do agente cuidador, apontando que a primeira ama então cuida, enquanto que a segunda, cuida e por isso ama, "se a base da relação é o cuidado, então o cuidado deve ser interpretado pelos profissionais como o eixo principal da relação e posto acima de questões pessoais que possam prejudicar tal relação". (Gabeira e Zornig, 2013, p. 148). Ao que parece as cuidadoras parecem ter uma dificuldade em realizar o cuidado, pois partem das próprias exigências 
pessoais e emocionais, conforme essa fala da cuidadora 1, por exemplo quando se refere as dificuldades do trabalho:

Cuidadora 1: (...) até mesmo do cuidado, do sentar, do conversar, eles tem isso e tu em casa tu tem isso com teus filho né, tu te senta, tu conversa, tu tem tempo, é o que tá faltando aqui pra eles, o amor, o carinho, a atenção.

A partir das percepções das cuidadoras, identifica-se que estas avaliam o cuidado no abrigo partindo de referências pessoais, além disso, há a ansiedade frente a um contexto de repetidas separações que parece mobilizá-las. Devido a isso, a cuidadora pode encontrar uma defesa na atitude profissional mais mecânica, rígida, impessoal, que siga apenas as rotinas pré-estabelecidas (Gabeira e Zornig, 2013), o que também foi percebido também através dos turnos de observação. As atividades de cuidado normalmente eram rápidas, devido também a quantidade de crianças. Contudo, também se percebia uma afinação e um discurso singular para cada criança. Apesar dessas constatações, também se mostrou, a partir dos relatos, as possibilidades existentes nesse contexto, referente aos estreitamentos dos vínculos e a capacidade das cuidadoras reconhecerem aspectos particulares e singulares dos bebês e crianças pequenas. Nos contextos das instituições é possível manter os marcadores simbólicos, desde que nesse contexto coletivo seja possível identificar aspectos singulares. (Zornig e Levy, 2008). Seguem as falas das cuidadoras:

Cuidadora 5: é um chorinho de dor, é um chorinho de manha, sabe, identifico o choro um do outro, por mais que tenha bastante criança. Mas tu tá sentada aqui e escuta ó: fulano tá chorando, ciclano tá chorando.

Cuidadora 1: É tem criança que entra e tem jeito para dormir com o travesseiro assim, dorme com o pano no rosto é tudo assim, eles mesmo vão te passando, nas atitudes... As crianças mostram o que querem. A gente tem a limitação, e criança também, tu tem que dar limite, mas tu tem que saber, observar, cuidar, escutar pra ver o que cada criança sente.

Cuidadora 2: só pelo choro a gente já sabe quem é, pelo choro a gente já identifica quem deles é (...).

Ou seja, além de impossibilidades neste contexto que foram expressas pelas cuidadoras, é possível pensar que, nos detalhes, seu trabalho também pode vir a ser potente. As falas acima citadas são exemplos de expressões singulares dentro do coletivo. Assim, Albano (2011) menciona que é preciso que o cuidador perceba o bebê e as crianças pequenas com suas particularidades, o que dará a possibilidade de que exista uma rede de significados com sentidos próprios e singulares na relação com cada bebê. Entretanto, é preciso refletir também sobre a falta da narratividade tanto em relação aos momentos do dia a dia, bem aquelas em relação as histórias de vida.

Conforme Alencar (2015) os bebês e as crianças pequenas que necessitam da medida do acolhimento tiveram suas histórias de vidas marcadas por uma separação. Portanto, é o adulto cuidador que auxiliará a mesma a compreender o que aconteceu, do por que não estão com suas famílias e por que estão na instituição de acolhimento. A partir desse entendimento a questão do "falar" com o bebê torna-se imprescindível, pois eles têm direito a saber de suas histórias, compreendendo que o abrigo será seu lugar de cuidado dentro do período que for preciso. O processo que nos dá a condição humana passa necessariamente pela palavra, que "tem o poder de causar, de criar ligações, de produzir alterações anátomofuncionais e neuroquímicas" (Motta, 2006, p. 54). Assim, trazemos falas das percepções das cuidadoras acerca da narratividade:

Cuidadora 5: Eu acho até que a gente deveria conversar todos os dias, que aqui não é a casa deles, fixa, aqui é a 
casa de passagem que mais cedo ou mais tarde eles vão ganhar.

Cuidadora 3: Mesmo a orientação que a gente tem né, a gente vai dar banho e vai trocar, né, "agora a tia vai dar banho”, sempre tá explicando. Só que agora não tem como. (...) "Agora a tia vai lavar o pé", "agora tu vai trocar porque fez cocô, fez xixi”, tudo que a gente faz tem que ser explicado, só que no momento essa demanda de criança aqui muitas vezes fica difícil.

Zornig e Levy (2008) relembram que apesar da constatação da importância das primeiras relações para o desenvolvimento físico e psíquico, é relevante lembrar do potencial criativo do ser humano. Pois não necessariamente um evento torna-se traumático por si só, mas sim aquilo que é vazio de simbolização. Assim, Albano (2011) aponta que para se manter vivo, os bebês e crianças pequenas precisam de alguém que dê suporte as suas necessidades físicas, mas para além dessas necessidades orgânicas, "um adulto que o introduza no universo das trocas afetivas". (Albano, 2011, p. 32). A partir dos pressupostos winnicotianos, entende-se que o bebê inicia sua construção subjetiva com uma relação próxima, afetiva e íntima. A capacidade de interpretar o que a criança sente e falar sobre as suas experiências configura-se como um envelope, que sustenta física e psiquicamente o bebê. (Zornig e Levy, 2008)

Deste modo, Luvizaro e Galheigo (2011) apontam que dentre as dificuldades de concretização de um cuidado integral, para além de ofertar um espaço de moradia e de proteção, uma das dificuldades é concretizar de forma efetiva a atenção e escuta aos percursos singulares das crianças que estão nos programas de acolhimento institucional. Cintra (2010) também aponta que para além de documentos e leis é preciso, no cotidiano dos abrigos, incitar práticas que busquem a singularidade. $\mathrm{O}$ acolhimento não deve representar uma limitação do mundo subjetivo da criança.

Pode-se refletir que há um entrelaçamento das categorias analisadas, que indicam as percepções das cuidadoras sobre o seu papel e sobre o cuidado. Nesta categoria foi possível pensar que a falta de interações afetivas na dimensão temporal de cuidado apontada pelas profissionais, para além de uma sobrecarga de trabalho podem estar dizendo de uma necessidade de se manter distante, como forma de preservar a saúde mental. E, portanto, nos relembram Dejours e Abdoucheli (1993) que as estratégias defensivas utilizadas por um coletivo de trabalho configuram-se em operações mentais utilizadas pelos trabalhadores para dar conta de uma realidade que faz sofrer, entretanto, diante dessa incapacidade e impossibilidade de uma relação mais próxima existem implicações para o cuidado dos bebês e crianças pequenas.

\section{Conclusão}

Propondo-se a conhecer a relação das cuidadoras com os bebês e crianças pequenas a partir das percepções das profissionais sobre o seu fazer, discutiu-se sobre as separações frequentes no cotidiano do abrigo e a percepção das cuidadoras de estarem fracassando. Tais evidências, demonstram a importância de cuidar desse ambiente humano que representa o contexto de desenvolvimento dos bebês e crianças pequenas que tem um período da sua vida interpelados pelo acolhimento. Compreendeu-se, a partir das percepções das cuidadoras sobre as relações que estabelecem com os bebês e crianças pequenas, que existe um investimento e construção de relações afetivas e significativas nesse contexto, todavia, a ansiedade e a falta de espaços de escuta frente a futuras separações tende a contribuir para atitudes mais distantes.

Assim, foi possível pensar que a percepção das profissionais de "falta de tempo" de interações afetivas e de qualidade dentro do ambiente coletivo de cuidado diz respeito a necessidade de se manterem distantes afetivamente, reflexão que encontra amparo no 
estudo de Zornig (2010). Já que a realidade institucional é marcada por separações e rupturas, sendo a necessidade de novos investimentos frequente, entende-se que uma das possiblidades é que elas estejam utilizando estratégias defensivas. Soma-se a isso, a falta de percepção clara da sua atuação e prática em relação ao cuidar, já as falas das cuidadoras demonstram que ao avaliar o cuidar e as relações partem das exigências pessoais. Destarte, as cuidadoras têm uma atuação mais voltada para a rotina pré-estabelecida e aos cuidados e necessidades físicas dos bebês e crianças pequenas.

Com essas considerações é preciso continuamente pensar nos espaços de formação dos trabalhadores do abrigo, além destes, espaços de sustentação também se configuram em estratégias importantes para tentar "dar conta" de um cotidiano de trabalho mobilizador (Seguim e Daffre, 2006). É muito importante cuidar do ambiente que receberá bebês e crianças pequenas, em relação aos aspectos físicos deste ambiente, contudo, sendo essencial cuidar dos adultos que estão encarregados da difícil tarefa de cuidar Albano (2011). Nesse sentido, ao considerarmos que essas mulheres cuidadoras possam estar lançando mão de estratégias defensivas para não se envolverem demasiadamente com as crianças (visto haverá uma ruptura à frente) significa que estamos implicados com o desenvolvimento dos bebês e das crianças pequenas e com a saúde mental das cuidadoras. Portanto, existe uma implicação ética na discussão, que perpassa tanto a via da saúde mental das cuidadoras quanto a possibilidade de que os bebês e crianças pequenas que vivenciam a realidade institucional possam se desenvolver através de relações afetuosas.

Aponta-se também que é preciso pensar em novas estratégias de cuidado em relação ao bebê e a criança pequena, que não apenas o acolhimento institucional (Cavalcante, 2008).
Em outros países, a partir da constatação da importância dos primeiros anos de vida, existem outras práticas como por exemplo, as famílias acolhedoras, uma prática ainda muito tímida dentro da realidade brasileira. (RossettiFerreira et al., 2012). Na realidade institucional pesquisada algumas impossibilidades foram apresentadas, sendo que essas podem influenciar o desenvolvimento afetivo e psíquico dos bebês e crianças pequenas. Além disso, torna-se evidente a necessidade de cuidar das profissionais que cuidam, tendo em vista as particularidades do seu trabalho.

Por fim, considera-se que a pesquisa cumpriu com os objetivos que se propunha, conhecer aspectos da relação desse par, refletindo sobre as percepções das cuidadoras frente a relação estabelecida com os bebês e crianças pequenas, não enquanto verdades absolutas, mas contextualizadas, e de forma que suscitem ainda mais questionamentos e investigações nesse campo. Cintra (2010) aponta que é função do pesquisador abordar e problematizar as questões que foram propostas enquanto objetivo de pesquisa, no entanto, é impossível esgotá-las, especialmente num contexto tão plural como as instituições de acolhimento, pois as práticas cotidianas e as relações nessas instituições não se deixam apreender em sua totalidade. Neste contexto específico pesquisado, compreendeu-se que o contato cotidiano com bebês e crianças pequenas torna a instituição de acolhimento um local mobilizador para os cuidadores que ali atuam. Ademais, o desafio de lidar com o individual e o personalizado neste ambiente coletivo que é o abrigo impõe a necessidade de um olhar atento a essa questão para que se concretize um cuidado efetivamente integral. É com esta constatação que se faz importante continuar pensando e refletindo nesses encontros que acontecem nas instituições de acolhimento, para que estes sejam marcados por relações afetivas significativas e de qualidade.

\section{Referências}

Albano, P. (2011). O que é um bebê? In: F.

Nogueira (org.), Entre o singular e o 
coletivo: $O$ acolhimento de bebês em abrigos (pp. 32-45). São Paulo: Instituto

Fazendo História.

Alencar, R. (Coord.). (2015). O acolhimento de bebês: práticas e reflexões compartilhadas. São Paulo: Instituto Fazendo História. Recuperado de: http://primeirainfancia.org.br/wpcontent/uploads/2015/03/acolhimento-debebes.pdf

Bardin, L. (1977). Análise de conteúdo. Lisboa: Edições 70.

Bentzen, W. R. (2012). Guia para observação e registro do comportamento infantil (Trad.: All Tasks). São Paulo: Cengage Learning.

Bowlby, J. (2006). Cuidados maternos e saúde mental. ( $5^{\mathrm{a}}$ ed.). São Paulo: Martins Fontes. (Original publicado em 1951).

Bowlby, J. (1990). Formação e rompimento dos laços afetivos. ( $2^{\mathrm{a}}$ ed.). São Paulo: Martins Fontes.

Brasil. (1990). Estatuto da Criança e do Adolescente. Lei 8.069, de 13 jul. 1990. Diário Oficial da República Federativa do Brasil. Brasília/DF.

Brasil. (2006). Plano Nacional de Promoção, Proteção e Defesa do Direito de Crianças e Adolescentes à Convivência Familiar e Comunitária. Brasília/DF.

Brazelton, T. B., \& Greenspan, S. I. (2002). As necessidades essenciais das crianças: o que toda criança precisa para crescer, aprender e se desenvolver. Porto Alegre: Artmed.

Careta, D. S. (2011). Quando o ambiente é o abrigo: cuidando das cuidadoras de crianças em acolhimento institucional. Tese de Doutorado (Instituto de Psicologia da Universidade de São Paulo). Universidade de São Paulo, São Paulo.

Cavalcante, L. I. (2008). Ecologia do cuidado: interações entre a criança, o ambiente, os adultos e seus pares em instituição de Abrigo. Tese de Doutorado (Teoria e Pesquisa do Comportamento) Universidade Federal do Pará, Belém.

Cavalcante, L. I. C., Magalhães, C. M. C., \& Pontes, F. A. R. (2007). Abrigo para crianças de 0 a 6 anos: um olhar sobre as diferentes concepções e suas interfaces. Revista Mal Estar e Subjetividade, 7(2), 329-352. Recuperado de:

http://pepsic.bvsalud.org/scielo.php?script= sci_arttext\&pid=S151861482007000200006

Cintra, A. L. (2010). Corpo a corpo: representações identitárias, singularidades e abrigos institucionais para crianças. Dissertação (Programa de Pós-Graduação em Psicologia - Mestrado) - Universidade Federal de Santa Catarina, Florianópolis.

Conselho Nacional dos Direitos da Criança e do Adolescente/Conselho Nacional de Assistência Social. (2009). Orientações técnicas: Serviços de Acolhimento para Crianças e Adolescentes. Brasília/DF.

Dejours, C., \& Abdoucheli, E. (1993). Itinerário teórico em psicopatologia do trabalho. In: C. Dejours, E, Abdoucheli, \& C. Jayet. Psicodinâmica do trabalho: contribuições da Escola Dejouriana à análise da relação prazer, sofrimento e trabalho (pp. 119-145). São Paulo: Atlas.

França, D. B. (2008). Mãe social: o mito da reprodução do amor materno nas instituições de abrigo. In: L. M., Atem (Org.). Cuidados no início da vida: clínica, instituição, pesquisa e metapsicologia (pp. 91-99). São Paulo: Casa do Psicólogo.

Gabeira, T. R., \& Zornig, S. A. (2013). Os eixos do cuidado na primeira infância. Cadernos de psicanálise (Rio de Janeiro), 35(29), 143-158. Recuperado de http://pepsic.bvsalud.org/scielo.php?script= sci_arttext\&pid=S141362952013000200009\&lng=pt\&tlng=pt.

Gaskell, G. (2003). Entrevistas individuais e grupais. In: M. W. Bauer, \& G. Gaskell (Orgs.), Pesquisa qualitativa com texto, imagem e som: um manual prático (pp.6489). ( $3^{\text {a }}$ ed.). Petrópolis: Vozes.

Gibbs, G. (2009). Anális e de dados qualitativos. Porto Alegre: Bookman.

Luvizaro, N. A., \& Galheigo, S. A. (2011). Considerações sobre o cotidiano e o habitar de crianças e adolescentes em situação de acolhimento institucional em abrigo. 
Revista De Terapia Ocupacional Da Universidade De São Paulo, 22(2), 191199. doi: $10.11606 /$ issn.22386149.v22i2p191-199

Marin, I. S. K. (2011). Prefácio. In: F, Nogueira (org.), Entre o singular e o coletivo: o acolhimento de bebês em abrigos (pp. 9-18). São Paulo: Instituto Fazendo História.

Motta, S. P. P. (2006). Ética e condição humana. In: R. G. Melgaço (org.), A ética na atenção ao bebê: Psicanálise - Saúde Educação (pp. 51-60). São Paulo: Casa do Psicólogo.

Moura, G. G., \& Amorim, K. S. (2013). A (in)visibilidade dos bebês na discussão sobre acolhimento institucional. Psicologia em Estudo, 18 (2), 235-245. Recuperado de http://www.redalyc.org/articulo.oa? $\mathrm{id}=2871$ 28992005

Moura, G. G. (2012). “Quem não pega, não se apega": O acolhimento institucional de bebês e as (im)possibilidades de construção de vínculos afetivos. Dissertação (Programa de Pós-Graduação em Psicologia da USP) Universidade de São Paulo, Ribeirão Preto $-\mathrm{SP}$.

Nogueira, F. (2011). Introdução. In: F. Nogueira (org.), Entre o singular e o coletivo: o acolhimento de bebês em abrigos (pp. 19-31). São Paulo: Instituto Fazendo História.

Rizzini, I., \& Rizzini, I. (2004). A institucionalização de crianças no Brasil: percurso histórico e desafios do presente. ( $2^{\mathrm{a}}$ ed.). Rio de Janeiro: PUC-RJ.

Rossetti-Ferreira, M. C., Almeida, I. G. D., Costa, N. R. D. A., Guimarães, L. D. A., Mariano, F. N., Teixeira, S. C. D. P., \& Serrano, S. A. (2012). Acolhimento de crianças e adolescentes em situações de abandono, violência e rupturas. Psicologia: Reflexão e Crítica, 25(2), 390-399. https://dx.doi.org/10.1590/S010279722012000200021

Seguim, C, \& Daffre, S. G. (2006). Cuidando do cuidador. In: R. G. Melgaço (Org.), A ética na atenção ao bebê: psicanálise saúde - educação (pp. 177-182). São Paulo: Casa do Psicólogo.

Siqueira, A. C., \& Dell'Aglio, D. D. (2010). Crianças e adolescentes institucionalizados: desempenho escolar, satisfação de vida e rede de apoio social. Psicologia: Teoria e Pesquisa, 26(3), 407-415. Recuperado de http://periodicos.unb.br/index.php/revistapt p/article/view/20721.

Spitz, R. A. (1979). O primeiro ano de vida. São Paulo: Martins Fontes.

Tinoco, V. (2007). O luto em instituições de abrigamento: um desafio para cuidadores temporários. Dissertação (Mestrado em Psicologia Clínica) - Pontifícia Universidade Católica de São Paulo. PUCSP.

Winnicott, D. W. (1982). O ambiente e os processos de maturação: estudos sobre a teoria do desenvolvimento emocional. Porto Alegre: Artes Médicas.

Zornig, S. A. (2010). Reflexões sobre uma ética do cuidado na primeira infância. Primórdios-CPRJ, 1(1), 15-26. Recuperado de http://www.cprj.com.br/primordios/1526 reflexoes.pdf.

Zornig, S. A., \& Levy, L. (2008). Uma criança em busca de uma janela: função materna e trauma. In: L. M. Atem (org.), Cuidados no início da vida: clínica, instituição, pesquisa e metapsicologia (pp. 71-82). São Paulo: Casa do Psicólogo. 


\section{Dados sobre os autores:}

- Isabela Cristina Lemos: Psicóloga, formada pela Universidade de Santa Cruz do Sul (UNISC). Atuou como estagiária no Serviço Integrado de Saúde (SIS), realizando atendimentos psicoterápicos individuais, acolhimentos e a coordenação de um grupo de apoio psicológico ao luto. As experiências pelo viés psicológico perpassam diversas instituições, CAPS infantojuvenil (experiência com grupos e oficinas); Instituição de acolhimento para crianças e adolescentes de 0 a 12 anos (grupos); em ambiente hospitalar no ambulatório acolhendo pacientes e familiares.

- Roselaine Berenice Ferreira da Silva: Doutora em Psicologia pela Pontifícia Universidade Católica do Rio Grande do Sul - PUCRS (2008). Professora-adjunta da Universidade de Santa Cruz do Sul (UNISC), no Curso de Psicologia, lecionando disciplinas relacionadas à Avaliação Psicológica. Realiza pesquisas com ênfase em Fundamentos e Medidas da Psicologia, atuando principalmente nos seguintes temas: Avaliação Psicológica, Desenvolvimento Infantil e Validação de Instrumentos Psicológicos. Coordenadora do Curso de Pós-Graduação em Avaliação Psicológica e do Laboratório de Mensuração e Testagem Psicológica da UNISC. Membro da International Test Commission (ITC). Diretora Científica e de Ensino da ProntyAssessoria Organizacional, desenvolvendo atividades de formação para Psicólogos, além de Avaliação Psicológica para fins de Seleção de Pessoal, Desenvolvimento de Talentos e de Liderança. Assessora Escritório de Advocacia Criminal com elaboração de laudos e pareceres psicológicos. 